\title{
V comme VARIANTE
}

Un manuscrit de Franz Liszt (1876)

\section{Marie-Laure Ingelaere}

\section{OpenEdition}

\section{Journals}

Édition électronique

URL : https://journals.openedition.org/rbnu/1842

DOI : $10.4000 /$ rbnu. 1842

ISSN : 2679-6104

Éditeur

Bibliothèque nationale et universitaire de Strasbourg

\section{Édition imprimée}

Date de publication : 1 mai 2014

Pagination : 74-75

ISBN : 9782859230524

ISSN : 2109-2761

Référence électronique

Marie-Laure Ingelaere, « V comme VARIANTE », La Revue de la BNU [En ligne], 9 | 2014, mis en ligne le 01 mai 2014, consulté le 22 mai 2021. URL : http://journals.openedition.org/rbnu/1842 ; DOI : https:// doi.org/10.4000/rbnu. 1842

\section{(c) (i) (2)(2)}

La Revue de la BNU est mise à disposition selon les termes de la Licence Creative Commons Attribution - Pas d'Utilisation Commerciale - Partage dans les Mêmes Conditions 4.0 International. 

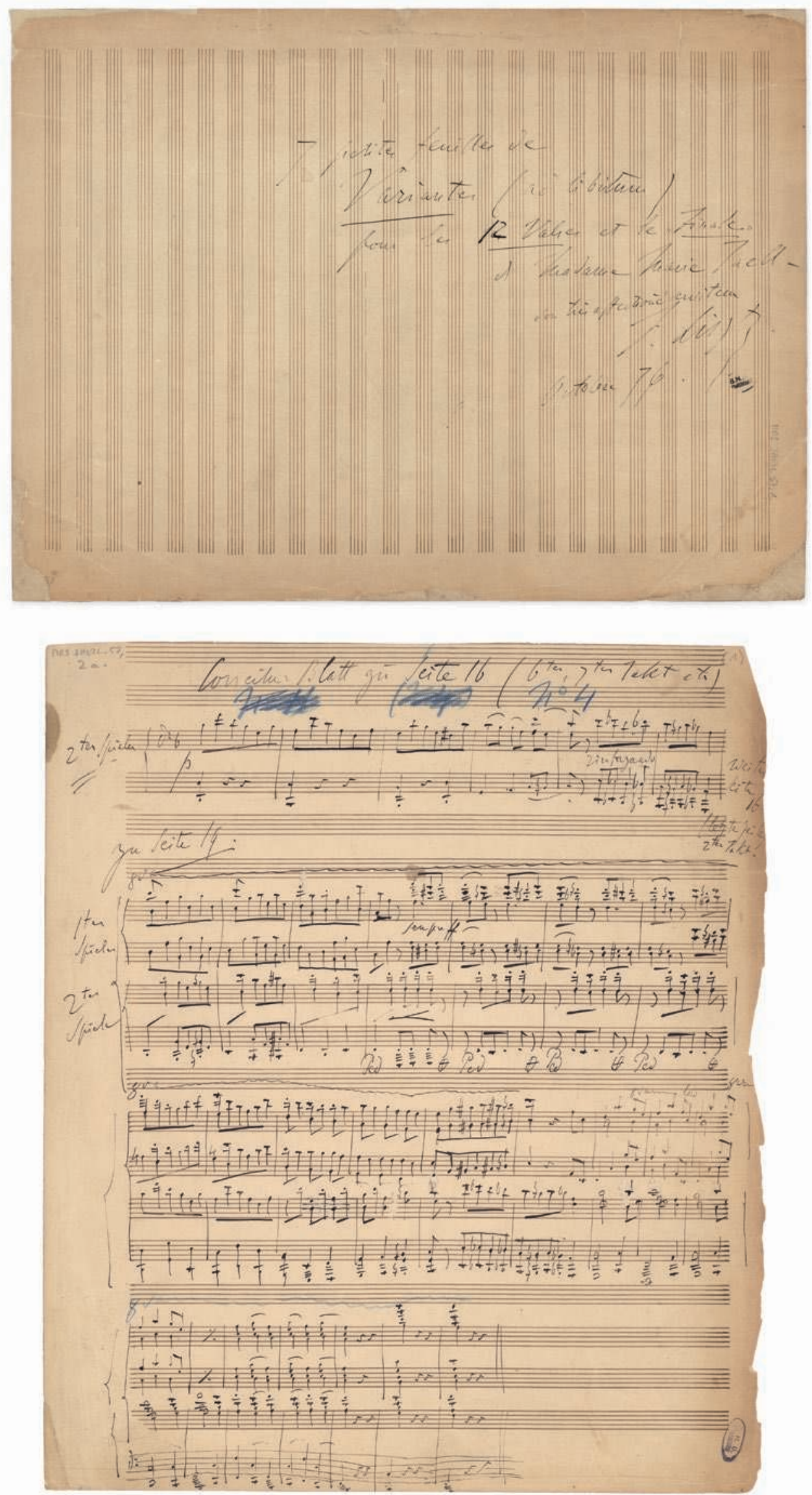

Page liminaire et première page de partition des variantes de Liszt (pour la Valse à quatre mains $\mathrm{n}^{\circ} 4$ ) 
Trésors de l'écrit : un abécédaire

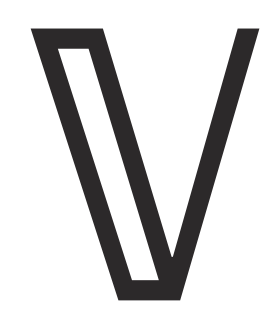

\section{VARIANTE}

\section{Un manuscrit de Franz Liszt (I876)}

"Forme ou solution légèrement différente mais voisine " : telle est la définition du terme " variante " selon le Petit Robert. Un manuscrit de Franz Liszt conservé par la BNU dans les archives de Marie Jaëll (1846-1925), pianiste, compositrice et pédagogue d'origine alsacienne, va nous donner l'occasion d'explorer ce mot banal à première vue.

Ce manuscrit est une partition constituée de plusieurs feuilles de papier à musique. Sur la première page, en travers de la feuille prise dans le sens de la largeur, d'une grande écriture anguleuse, Liszt dédicace l'ensemble à Marie Jaëll qu'il apprécie beaucoup : 7 petites feuilles de Variantes (ad libitum) pour les 12 Valses et le Finale de Madame Marie Jaëll - Son très affectueux serviteur, F. Liszt, octobre 76.

Le mot "Variantes ", écrit en caractères plus grands, se détache nettement. Suivent six feuilles reprenant des passages de l'une des principales œuvres de Marie Jaëll, les Valses à quatre mains, op. 8, composées en 1876 et dont l'édition était vivement soutenue par Liszt qui écrivait à Alfred Jaëll (1832-1882), son époux, pianiste lui aussi : " Sous forme de Valses et Ländler, Madame Jaëll a composé un collier de fines perles musicales [...] Veuillez bien dire à Madame Jaëll mes sincères louanges et les vôtres de ce charmant bijou. Si Leuckard avait la maladresse de ne pas s'en emparer vite, je trouverais aisément un autre éditeur convenable ${ }^{1}$. Ces valses, qui ont eu un grand succès à l'époque, ont effectivement été éditées tout d'abord à Leipzig par Leuckard, puis à Paris par Gérard en 1877 et à Milan en 1878. Elles ont été créées à Paris par leur auteur et son mari le 14 mars $1877^{2}$ et à cette occasion, on salua même le " second début " de Marie Jaëll comme compositeur. Franz Liszt en personne les a interprétées avec Camille Saint-Saëns à Bayreuth en $1876^{3}$.

L'œuvre, accompagnée de poésies, est composée de douze valses et d'un finale, pièces qui ne sont pas toutes l'objet des propositions de "variantes " faites par Liszt : celles-ci ne concernent en effet que les valses $4,5,6,10,11,12$ et le finale. Non seulement il ne s'agit que de modifications limitées mais de plus, Liszt précise d'emblée " ad libitum ", laissant ainsi à la dédicataire la liberté de choisir la version qui lui plaira le plus.
Le souci de Liszt de ne pas heurter de front la sensibilité de Marie Jaëll est perceptible ; il connaissait certainement son caractère entier quand, malgré sa propre notoriété, il lui écrivait quelques semaines plus tard, le 3 novembre 1876 : « En vous envoyant ces annotations de votre charmante œuvre, je craignais bien de manquer au précepte connu : "surtout pas trop de zèle". Il va sans dire que ces annotations n'avaient d'autre but que de vous témoigner ma sincère affection. Si quelques-unes vous paraissent convenables, tant mieux ; rejetez les autres sans façon quelconque, selon votre bon plaisir qui sera toujours le meilleur" 4 . Les "variantes" deviennent ici prudemment des " annotations ", et dans une autre lettre une " révision ". En tout cas, elles sont l'occasion de découvrir la délicatesse du grand compositeur envers une jeune femme qu'il aurait pu juger inexpérimentée ! Dès cette époque, une véritable estime liait Liszt - un ami de longue date d'Alfred Jaëll - et la compositrice qui sera la première en 1891 à donner à Paris une intégrale de ses œuvres pour piano, intégrale pour laquelle elle écrivit un programme commenté d'une certaine envergure 5 .

Ces feuilles de papier à musique nous révèlent bien évidemment aussi Liszt comme professeur de composition et elles mériteraient certainement d'être étudiées à ce titre. Cependant, c'est d'abord le respect mutuel au-delà des générations, la délicatesse, l'estime et, finalement, une certaine bonté d'âme que manifestent ces «variantes" : un mot riche de sens !

\footnotetext{
Marie-Laure Ingelaere

1 - Lettre de Liszt à Alfred Jaëll, Weimar, 22 juin 1876, publiée par J. Chantavoine : Lettres inédites de Liszt à Alfred et Marie Jaëll, in Revue internationale de musique, $1952, \mathrm{n}^{\circ} 12, \mathrm{p} .35$

2 - Revue et gazette musicale de Paris, 18 mars 1877

3 - Lettre d'Alfred Jaëll à Liszt, Vichy, 6 septembre 1876, publiée par J. Chantavoine, op. cit., p. 36

4- Lettre de Liszt à M. et Mme Jaëll, Budapest, 3 novembre 1876 , publiée par J. Chantavoine, op. cit., p. 37

5- Euvres originales pour piano de Liszt... 1891. Paris, Chaix, 1891, $32 \mathrm{p}$. Audition des œuvres originales pour piano de Liszt... Salle Pleyel, 1892. Paris, Chaix, 1892, [40] p.
} 